\title{
Flow Characteristics and Energy Dissipation Over Single Step Broad - Crested Weirs
}

\author{
Shareef \\ Assist. Professor \\ Technical College/ \\ Mosul
}

Dr. Hamid H. Hussein

\author{
Lecturer \\ Engineering College \\ University of Mosul
}

Inam A. K. Juma
Saleh J. S.

\author{
Assist. Lecturer \\ Technical College/ \\ Mosul
}

\begin{abstract}
The main purpose of traditional broad - crested weir is to rise and control upstream (U/S) water level. In this study a new performance was added to this weir, by making it as an energy dissipater. In order to study the energy dissipation percent $(E \%)$, the downstream $(\mathrm{D} / \mathrm{S})$ height of the weir $(12 \mathrm{cms} U / \mathrm{S}$ height) was reduced four times as $9.8,8,6$ and3.8cms. Thirty experiments were performed in a laboratory horizontal channel of $12 \mathrm{~m}$ length, $0.5 \mathrm{~m}$ width and $0.45 \mathrm{~m}$ depth for a wide range of discharge.

A mathematical model to compute theoretical coefficient of discharge (Cdth) was modified depending upon momentum equations. Experimental results gave a high validity to the computed values of the proposed model. On the other hand, three empirical non dimensional relations were obtained. The first is liner relation to estimate the ratio for $\mathrm{D} / \mathrm{S}$ water head to $\mathrm{U} / \mathrm{S}$ weir height $(\mathrm{h} / \mathrm{P1})$ in terms of the ratio for $U / S$ water head to $U / S$ weir height $(H / P 1)$. The second relation is nonlinear relation to estimate the discharge coefficient $(\mathrm{Cd})$ in terms of $\mathrm{H} / \mathrm{P1}$ and the ratio of $\mathrm{D} / \mathrm{S}$ weir height to $\mathrm{U} / \mathrm{S}$ weir height $(\mathrm{P} 2 / \mathrm{P1})$. While the third relation is to estimate $\mathrm{E} \%$ in terms of h/P1and P2/P1 with high correlation coefficients. The experimental results of the study showed that $\mathrm{E} \%$ increased up to $46 \%$. Furthermore, Cd was improved and gets higher values in comparison with traditional weirs.
\end{abstract}

Key words: Hydraulic structure; Broad crested weirs ; Energy dissipation.

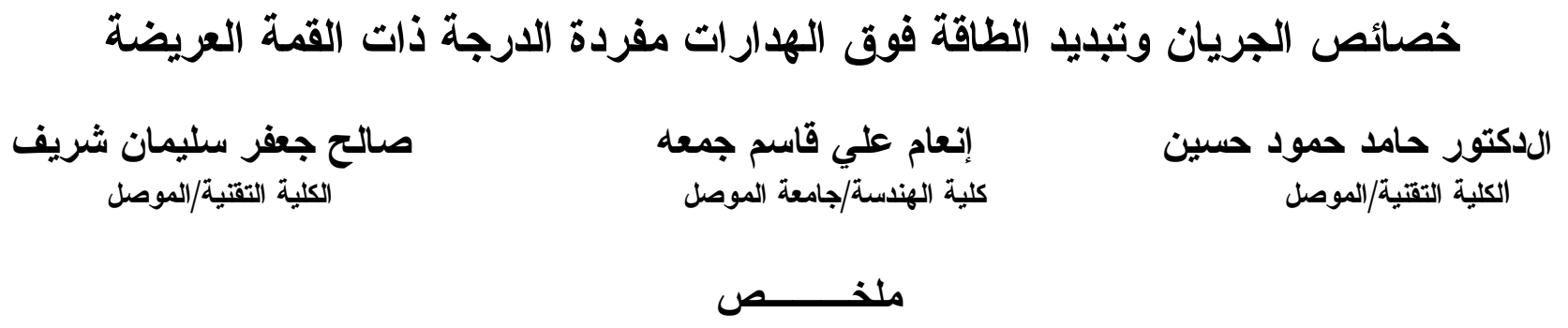

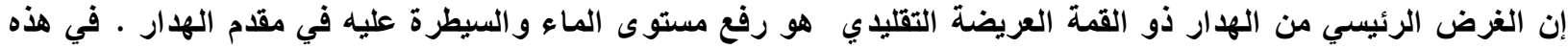

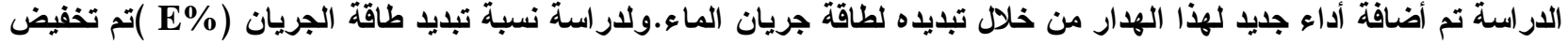

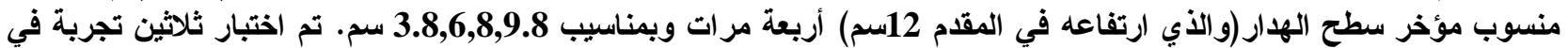

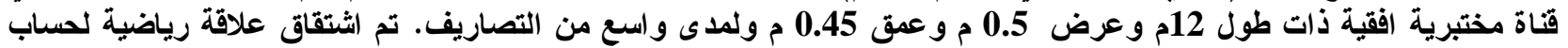

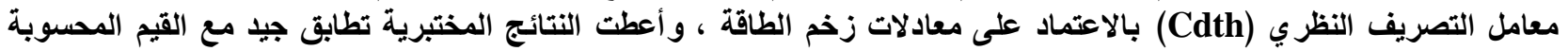

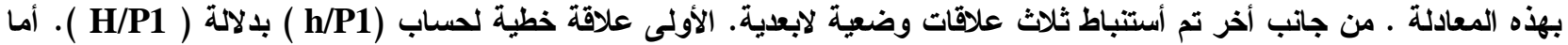

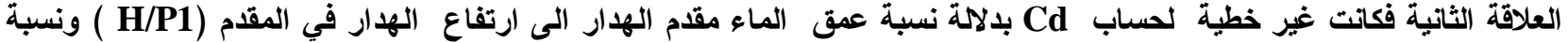

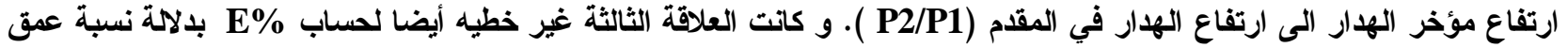

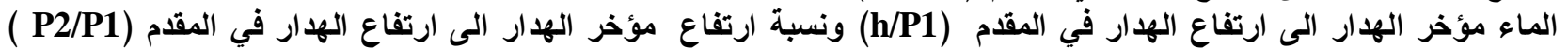

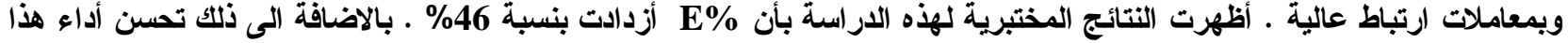

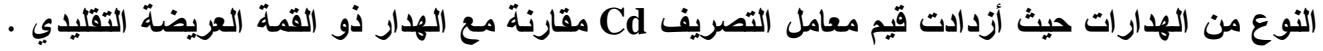




\section{Notation:}

The following symbols are used in this research:

$B=$ channel width,

$C d=$ weir discharge coefficient,

$E \%=$ energy dissipation ratio,

$F \tau_{o}=$ boundary shear force,

see figure (1),

$g=$ acceleration due to gravity,

$H=\mathrm{U} / \mathrm{S}$ water head above the crest,

$h=\mathrm{D} / \mathrm{s}$ water head,

$L=$ length of the weir,

$L_{2}=$ length of D/S step,

$P_{1}=\mathrm{U} / \mathrm{S}$ weir height,
$P_{2}=\mathrm{D} / \mathrm{S}$ weir height,

$q=$ discharge over the weir per

unit width,

$Q=$ Flow discharge,

$R=$ radius of $\mathrm{U} / \mathrm{S}$ corner of the weir,

$R n=$ Reynolds number

$V_{1}=$ velocity at sec. 1 ,

$V_{2}=$ velocity at sec. 2 ,

$\tau_{\mathrm{o}}=$ boundary shear stress,

$v=$ kinematics viscosity of water.

$\mu=$ dynamic viscosity,

\section{INTRODUCTION}

Weirs with various shapes have been considered the most hydraulic structures which used in open channel flow. They are widely used in water flow measurements and control of water surface levels.

In order to prevent erosion and scouring in downstream $(\mathrm{D} / \mathrm{S})$ ends of weirs, the hydraulic energy should be dissipated. For this purpose, several ways were used such as lining by rubbles and riprap, or by constructing steps at D/S ends of weirs (Chanson, 2001).

In recent years, various investigators study the characteristics of flow over broad- crested weirs , Rao and Rao , (1973) ; Ackers , et al. ( 1978 ) verified an empirical relations for discharge coefficient (Cd), with inclined upstream face of this weir . Clemens, et al., (1984) provided a simplified design procedure covering a wide range of variables. Ramamurthy, et al., (1988) studied the characteristics of round - nosed broad - crested weir under free flow and submerged flow conditions. They derived a mathematical expression from momentum relations for $(\mathrm{Cd})$. Furthermore, they found that when the ratio of the radius of $U / S$ corner $(\mathrm{R})$ to the height of the weir (P) $0.25 \leq \mathrm{R} / \mathrm{P} \leq 1$, the flow separation is essentially eliminated and $(\mathrm{Cd})$ has attained the highest value. Chamani, (2002) presented a method for predicting both subcritical and supercritical flow characteristics over drops. He also derived an empirical relation to estimate the relative energy loss.. Gonzalez and Chanson, (2007) estimated (Cd) over a large broad - crested weir, two empirical relations were presented depending on the geometry of the weir. Al-Talib (2007) investigated in a laboratory study the stepped and unstepped weirs for steep slope channels which is having high difference in head of water between upstream and downstream in order to find their efficiency for dissipating flow energy. She found that stepped weirs are more efficient than unstepped weirs and the maximum energy dissipation ratio in stepped weirs was approximately $10 \%$ higher than in unstepped weirs. Noori and Juma (2008) obtained two empirical equations to estimate the value of discharge coefficient in terms of effective head to crest height ratio, upstream corner radius to crest height ratio and radius of cap to crest height ratio

In this paper, D/S height of traditional broad - crested weir was reduced. This reduction gave the weir a new performance by making it as a water level controller and energy dissipater. 
So, the main objectives of this paper are to study the flow characteristics, and dissipation energy $\mathrm{D} / \mathrm{S}$ of the weir for mild slope channels or zero slope channels. Furthermore, to develop a mathematical relation of theoretical discharge coefficient depending on momentum equations. Also, to modify empirical relations for discharge coefficient and percentage of energy dissipation depending on affecting factors.

\section{THEORETICAL ANALYSIS}

\section{1 -Experimental discharge coefficient, $\mathrm{Cd}$}

The functional relationship for Cd linking the main flow parameters (Figure 1) may be expressed as follows:

$$
f l\left(q, H, P_{1}, L, R, P_{2}, L_{2}, g, v\right)=0
$$

In which:

$\mathrm{q}=$ discharge over the weir per unit width,

$\mathrm{H}=\mathrm{U} / \mathrm{S}$ water head above the weir crest,

$\mathrm{P}_{1}=\mathrm{U} / \mathrm{S}$ weir height,

$\mathrm{L}=$ length of the weir,

$\mathrm{R}=$ radius of $\mathrm{U} / \mathrm{S}$ corner of the weir,

$\mathrm{P}_{2}=\mathrm{D} / \mathrm{S}$ weir height,

$\mathrm{L}_{2}=$ length of $\mathrm{D} / \mathrm{S}$ step,

$\mathrm{g}=$ acceleration due to gravity,

$v=$ kinematics viscosity of water.

By dimensional analysis:-

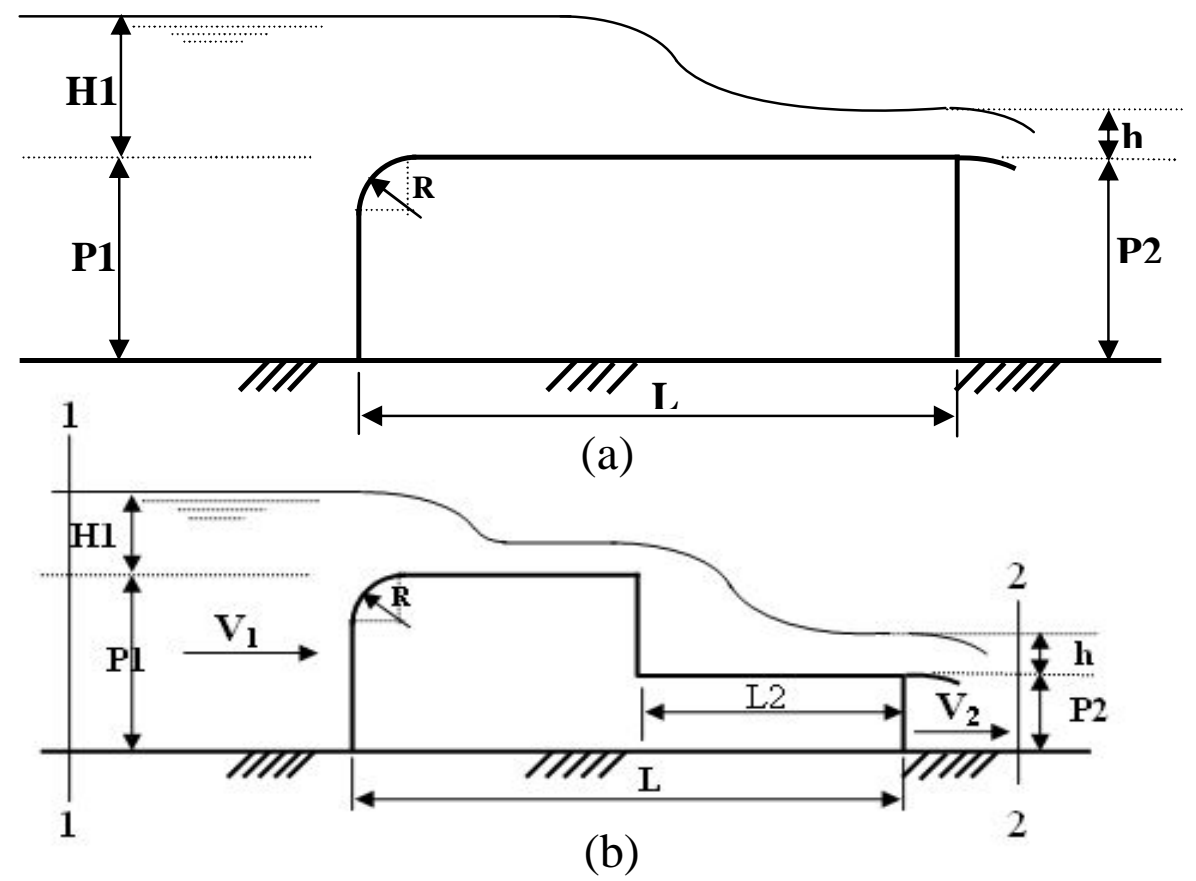

Fig. (1) Free flow over Broad-crested weirs : (a) Traditional round-nosed weir; (b) Stepped weir. 
$C d=\frac{q}{\frac{2}{3} H \sqrt{\frac{2}{3} g H}}=f_{2}\left(\frac{H}{P_{1}}, \frac{L}{P_{1}}, \frac{R}{P_{1}}, \frac{P_{2}}{P_{1}}, \frac{L_{2}}{P_{1}}, R n\right)$

$R n=$ Reynolds number which has very large values and hence its effect on $C d$ will be very little, therefore, $R n$ will be neglected in this study.

Since, $\mathrm{L} ; \mathrm{L}_{2} ; \mathrm{P}_{1}$ and $\mathrm{R}$ are fixed in this study then equation (2) can be rewritten as:-

$C d=f_{3}\left(\frac{H}{P_{1}}, \frac{P_{2}}{P_{1}}\right)$

\section{2 - Theoretical discharge coefficient, Cdth}

Ramamurthy, et al., (1988) introduced the following equation in their study to calculate Cdth, but they neglect the effect of boundary shear over the surface of the weir.

$F_{1}+M_{1}=F_{p}+F_{3}+M_{3}$

Where:

$F_{1}=\frac{\gamma}{2}\left(H+P_{1}\right)^{2} B$

$M_{1}=\frac{\gamma}{g}\left(\frac{Q^{2}}{\left(H+P_{1}\right) B}\right)$

$F_{p}=k p \frac{\gamma}{2}\left[P_{1}\left(2 H+P_{1}\right) B\right]$

$F_{3}=\frac{\gamma}{2} h^{2} B$

$M_{3}=\frac{\gamma Q^{2}}{g h B}$

The effect of boundary shear along the control surface over the weir was considered in this study and added to their equation.

$F_{1}+M_{1=} F_{P}+F_{3}+M_{3}+F \tau_{o}$

$F \tau_{o}=\tau_{o} \times B \times L=\mu \frac{d v}{d y} B L$

between sec. (1) and sec. (2) in Fig. (1)

$F \tau_{o}=\frac{V_{1}-V_{2}}{H-h} \times \mu \times B \times L$

Substituting $Q=V_{1} \times B \times H=V_{2} \times B \times h$ in Eq. (7) gets: 
$F \tau_{o}=\frac{-Q \mu L}{H \times h}$

In which:

$F \tau_{o}=$ boundary shear force,

$\tau_{\mathrm{o}}=$ boundary shear stress,

$Q=$ Flow discharge,

$V_{1}=$ velocity at sec. 1 ,

$V_{2}=$ velocity at sec. 2 ,

$B=$ channel width,

$L=$ weir length,

$\mu=$ dynamic viscosity,

$h=\mathrm{D} / \mathrm{s}$ water head.

The addition of equation (8) to equation (5) yields the following equation :

$$
\frac{\gamma}{2}\left(H+P_{1}\right)^{2} B+\frac{\gamma}{g}\left(\frac{Q^{2}}{\left(H+P_{1}\right) B}\right)=k p \frac{\gamma}{2}\left[P_{1}\left(2 H+P_{1}\right) B\right]+\frac{\gamma}{2} h^{2} B+\frac{\gamma Q^{2}}{g h B}-\frac{Q \mu L}{H h}
$$

$k p=0.98$ as proposed by Ramamurthy, et al., (1988).

Discharge for broad -crested weir is:

$Q=C d \frac{2}{3} H B \sqrt{\frac{2}{3} g H}$

Substituting equation (10) in (9) with simplification yields:-

$$
\left(H+P_{1}\right)^{2}-h^{2}-k p\left[2\left(2 H+P_{1}\right)\right]=\frac{16}{27} H^{3} C d^{2}\left[\frac{1}{h}-\frac{1}{H+P_{1}}\right]-\frac{4 \mu L}{3 \gamma h} \sqrt{\frac{2}{3} g H} C d
$$

Let:

$$
\begin{aligned}
\mathrm{A}_{1} & =\frac{16}{27} H^{3}\left[\frac{1}{h}-\frac{1}{H+P_{1}}\right] \\
\mathrm{A}_{2} & =\frac{4 \mu L}{3 \gamma h} \sqrt{\frac{2}{3} g H} \\
\mathrm{~A}_{3} & =\left(H+P_{1}\right)^{2}-h^{2}-k p\left[2\left(2 H+P_{1}\right)\right]
\end{aligned}
$$

Substituting A1, $\mathrm{A}_{2}, \mathrm{~A}_{3}$ in equation (11) gets:

$$
A_{1} C d^{2}-A_{2} C d-A_{3}=0
$$

The roots of equation (12) are given by quadratic equation as:

$$
C d_{1,2}=\frac{A_{2}}{2 A_{1}} \mp\left[\left(\frac{A_{2}}{2 A_{1}}\right)^{2}+\frac{A_{3}}{A_{1}}\right]^{1 / 2}
$$

Equation (13) will be used in this study to compute theoretical discharge coefficient (Cdth). 


\section{3 - Energy Dissipation Ratio, E\%}

Based on energy relationships, the general relationship for the flow energy dissipation can be verified:

Applying energy equations between section (1) and section (2) in Fig. (1) we get:

$$
\begin{aligned}
& E_{1}=P_{1}+H+{\frac{V_{1}}{2 g}}^{2} \\
& E_{2}=P_{2}+h+\frac{V_{2}^{2}}{2 g} \\
& E \%=\frac{E_{1}-E_{2}}{E_{1}} * 100 \%
\end{aligned}
$$

On the other hand, the functional relationship for E\% with the main flow parameters may be expressed as follows:

$E \%=f_{4}\left(q, P_{1}, H, P_{2}, h, g, L\right)$

By dimensional analysis:

$\mathrm{E} \%=f_{5}\left(\frac{H}{P_{1}}, \frac{P_{2}}{P_{1}}, \frac{h}{P_{1}}, \frac{L}{P_{1}}, \frac{q^{2}}{g \cdot h^{3}}\right)$

Since $L$ and $P_{l}$ are fixed and $h$ value related to $H$ and $q^{2} / g h^{3}$ which is the Froude number at section (2), then equation (18) becomes:-

$$
E \%=f_{6}\left(\frac{h}{P_{1}}, \frac{P_{2}}{P_{1}}, F r_{2}\right)
$$

\section{EXPERIMENTAL SET- UP AND PROCEDURE}

Tests were conducted in a horizontal, glass-walled rectangular channel of $10 \mathrm{~m}$ long, $0.50 \mathrm{~m}$ width and $0.45 \mathrm{~m}$ depth. Water surface levels were measured at different locations with an accurate point gauge reading to $0.1 \mathrm{~mm}$. Discharge was measured by a pre-calibrated sharpcrested weir installed at the channel inlet (Plate 1). U/S flow heads were started to measure at a location $(8 H) \mathrm{U} / \mathrm{S}$ of the weir model .Five weir models were manufactured from thermostone and painted to decrease the surface roughness of these models. To ensure stability of water surface levels and uniform flow with very low turbulence, the models were fixed at a distance of $3.5 \mathrm{~m}$ from the channel inlet.

One of the tested models was a traditional round - nosed broad - crested weir. It was $48 \mathrm{~cm}$ long, $50 \mathrm{~cm}$ width and $12 \mathrm{~cm}$ height, the radius of the round nose was $6 \mathrm{~cm}$. The other four models involved the above dimensions of the weir with D/S stepped length $L_{2}=24 \mathrm{~cm}$ and D/S height $P_{2}$ $=9.8,8,6$ and $3.8 \mathrm{cms}$.

All measurements were conducted at the center line of the channel width. In each test, U/S flow depth $(H)$, water surface levels, D/S flow depth over the step $(h)$, unit discharge $(q)$ were measured.

The measurements along the weir models were conducted under the free 
flow conditions. In all tests free-falling nappe at D/S step of models were fully aerated to prevent ventilation holes.

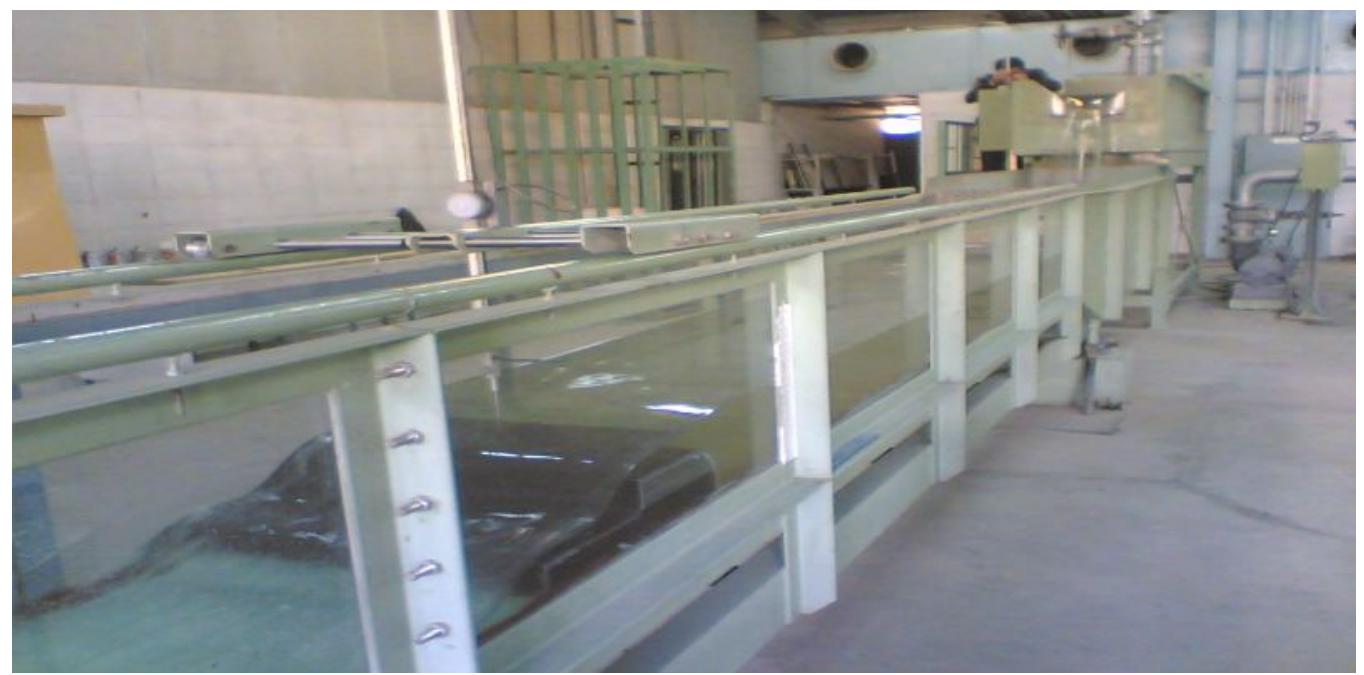

Plate (1) General view of the laboratory channel with one of the weir models

\section{RESULTS AND DISCUSSION}

\section{1- Water surface Profiles}

Dimensionless water surface profiles (w.s.ps.) over three weirs $(P 2 / P 1=1,0.5,0.32)$ were shown in Figures (2-4) which were measured in the center line of the channel. It can be seen that w.s.ps. were becomes horizontal when $X / P 1>2$ where $X$ is the U/S distance from the weir crest. These w.s.ps. were used to determine the average velocities and D/S water heads over the steps when w.s.ps. were essentially horizontal . The trend of these w.s.ps. were mostly similar, smooth and follow the shape of the weirs. Furthermore, in Figures (3) and (4) it can be seen clearly the effect of D/S steps on the w.s.ps.

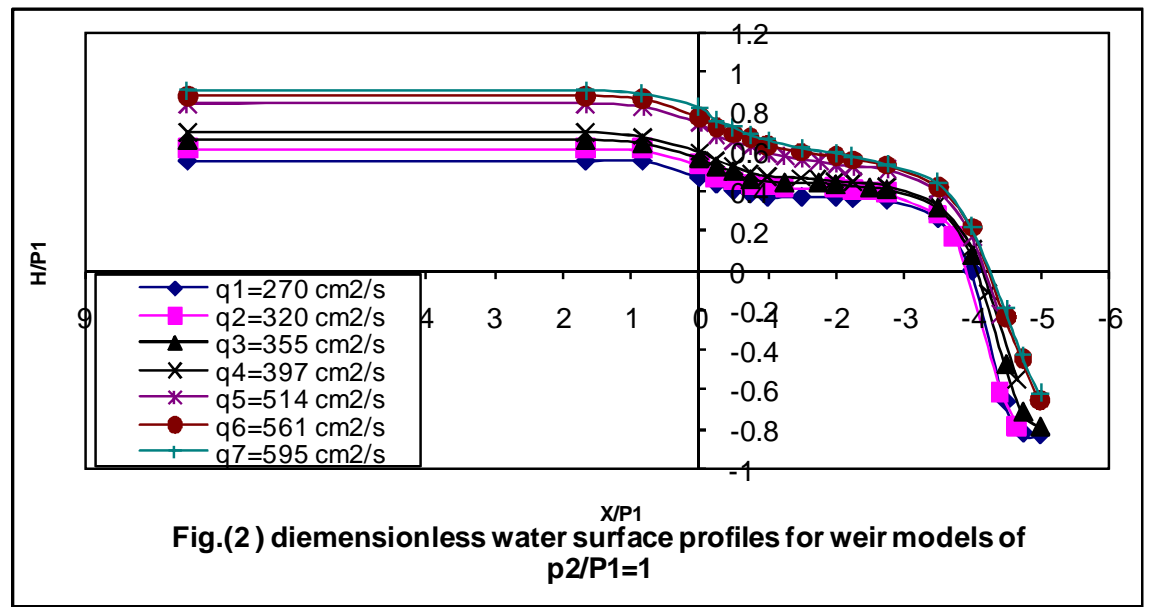



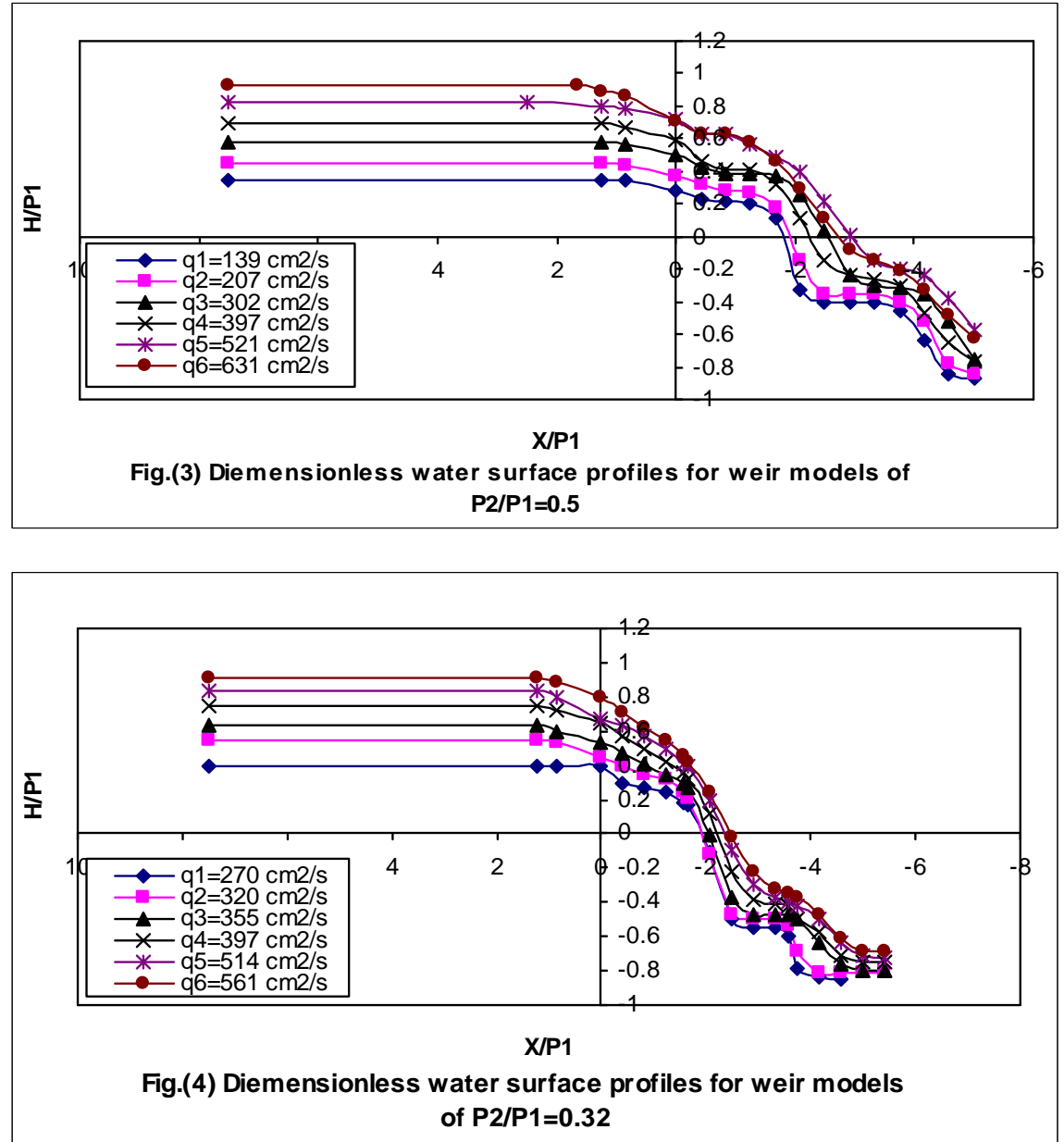

\section{2- Weir Coefficients of Discharge}

Figures (5) and (6) show the variation of experimental and theoretical $\mathrm{Cd}$ with $\mathrm{H} / \mathrm{P} 1$ for the weir models $(\mathrm{P} 2 / \mathrm{P} 1=1,0.5)$, which were obtained using equations 10 and 13 , respectively. In Fig. (5) for $(\mathrm{P} 2 / \mathrm{P} 1=1)$ the difference between experimental and theoretical $\mathrm{Cd}$ was about $4 \%$. While in Fig. (6) for $(\mathrm{P} 2 / \mathrm{P} 1=0.5)$ both values of $\mathrm{Cd}$ were nearly the same which gave a good agreement to the proposed model .

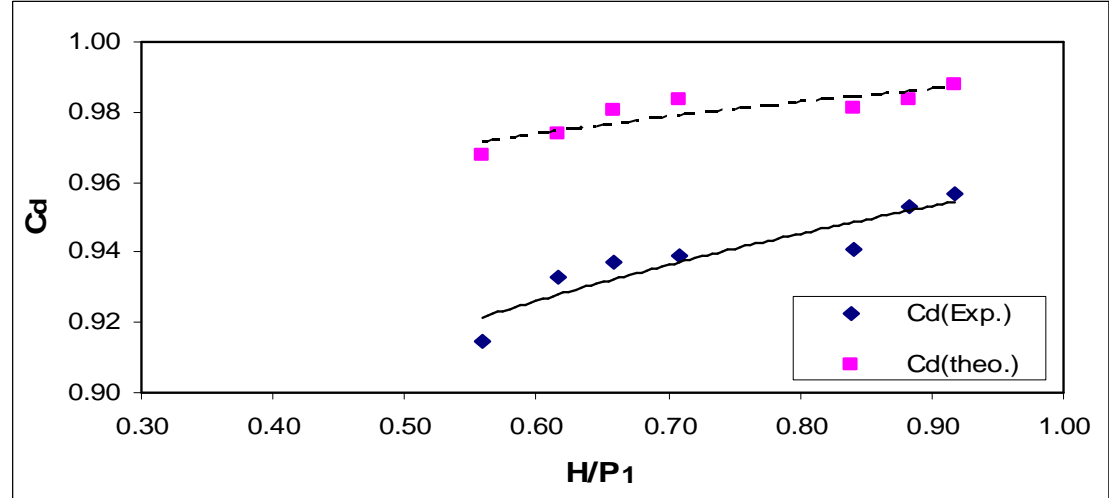

Fig.(5) Variation of Cd with $H / P_{1}$ for weir of $P_{2} / P_{1}=1$ 


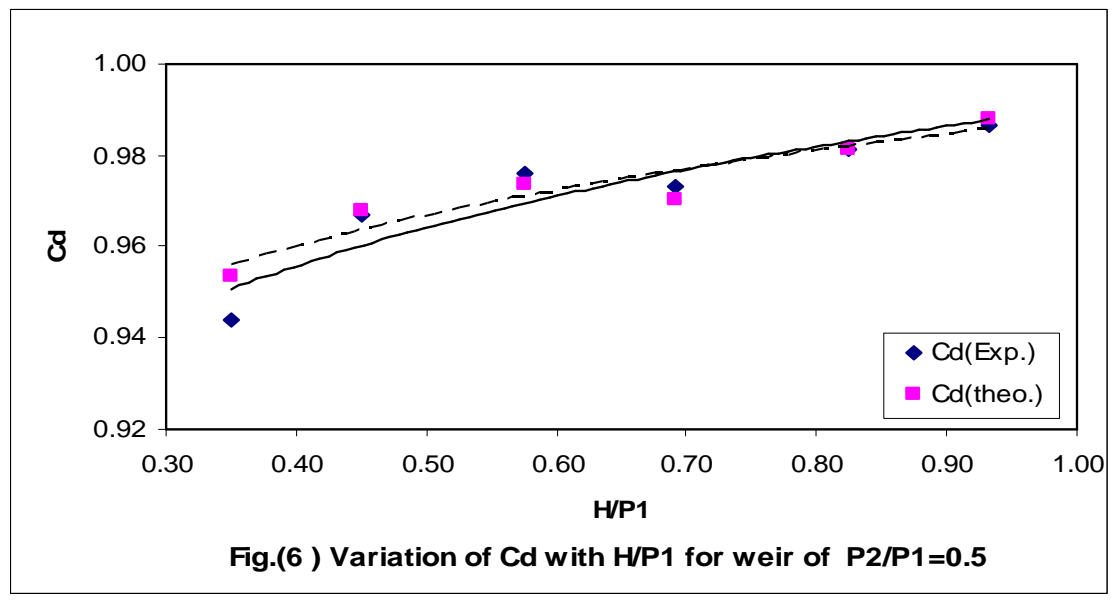

Also, in both figures, one may observe clearly that $\mathrm{Cd}$ increased significantly with the increase of $\mathrm{H} / \mathrm{P} 1$. The variations of experimental $\mathrm{Cd}$ with $\mathrm{H} / \mathrm{P} 1$ for the five models were shown in Fig. (7). Values of experimental $\mathrm{Cd}$ in all stepped models were obviously higher than experimental $\mathrm{Cd}$ in the traditional model (i.e., P2/P1=1). One may conclude that the presence of $\mathrm{D} / \mathrm{S}$ steps can be contributed to accelerate the water flow and increase $\mathrm{Cd}$.

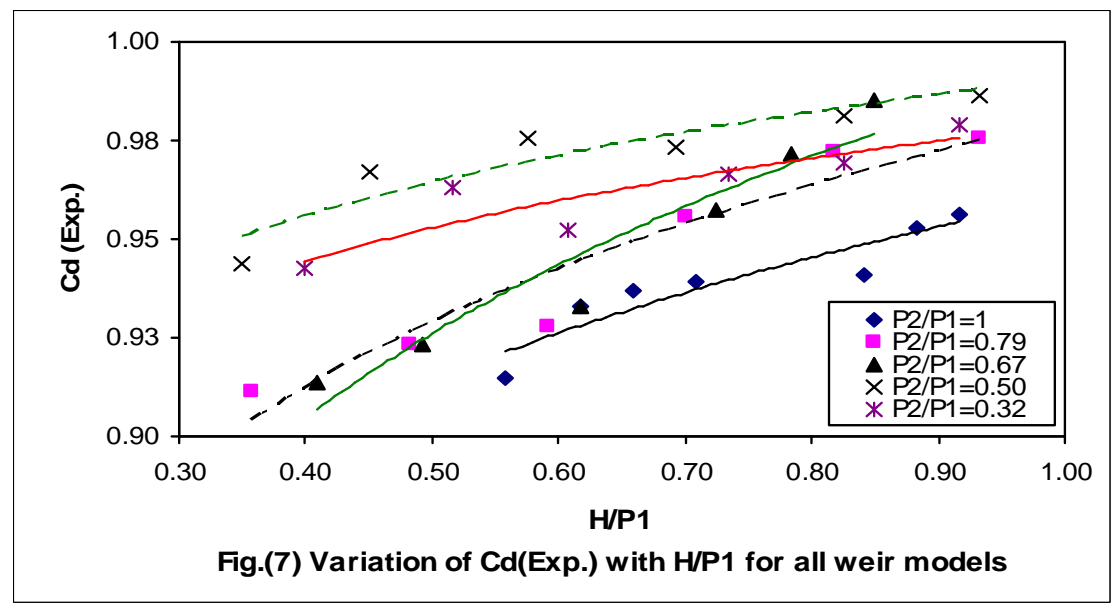

\section{3- Weir Energy Dissipation Ratio}

One of the main objectives of this study is to determine the influence of D/S weir steps on the energy dissipation ratio E\%. Fig. (8) Shows the effect of h/P1 and P2/P1 on E\%. In this figure $\mathrm{E} \%$ was decreased when $\mathrm{h} / \mathrm{P} 1$ was increased for the last two weir models of $\mathrm{P} 2 / \mathrm{P} 1=0.5$ and 0.32 , while for the other models E\% was approximately remains constant with the increase of $\mathrm{h} / \mathrm{P} 1$ because the difference between $\mathrm{P} 2$ and $\mathrm{p} 1$ is small. 


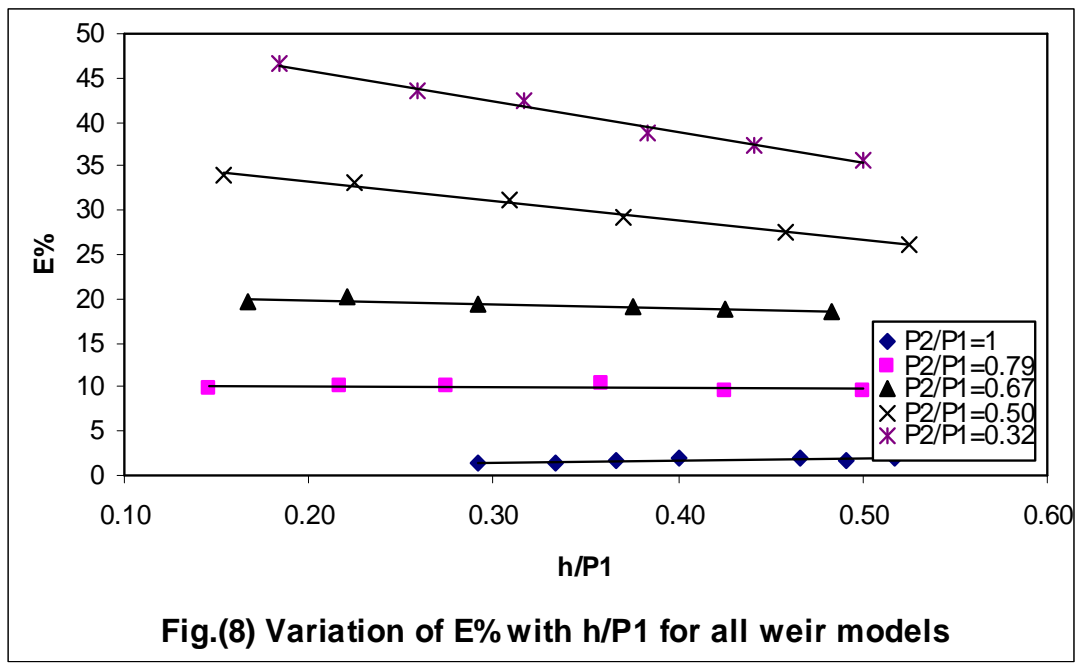

The variation of average values of $\mathrm{Cd}$ and $\mathrm{E} \%$ with $\mathrm{P} 2 / \mathrm{P} 1$ were shown in Fig. (9) from this figure it is observed clearly that both $\mathrm{Cd}$ and $\mathrm{E} \%$ were decreased with the increase of P2/P1. Also, it is observed that the average values of $\mathrm{Cd}$ and $\mathrm{E} \%$ at $\mathrm{P} 2 / \mathrm{P} 1=0.5$ and 0.32 were higher than the average values for other weirs respectively, generally $\mathrm{Cd}$ and $\mathrm{E} \%$ are inversely proportional with P2/P1 because increasing P2 makes the weir model to be approximately same as traditional weir. From this figure It is obvious that the weir of $\mathrm{P} 2 / \mathrm{P} 1=0.4$ gave $\mathrm{Cd}=0.968$ and $\mathrm{E} \%=37$.

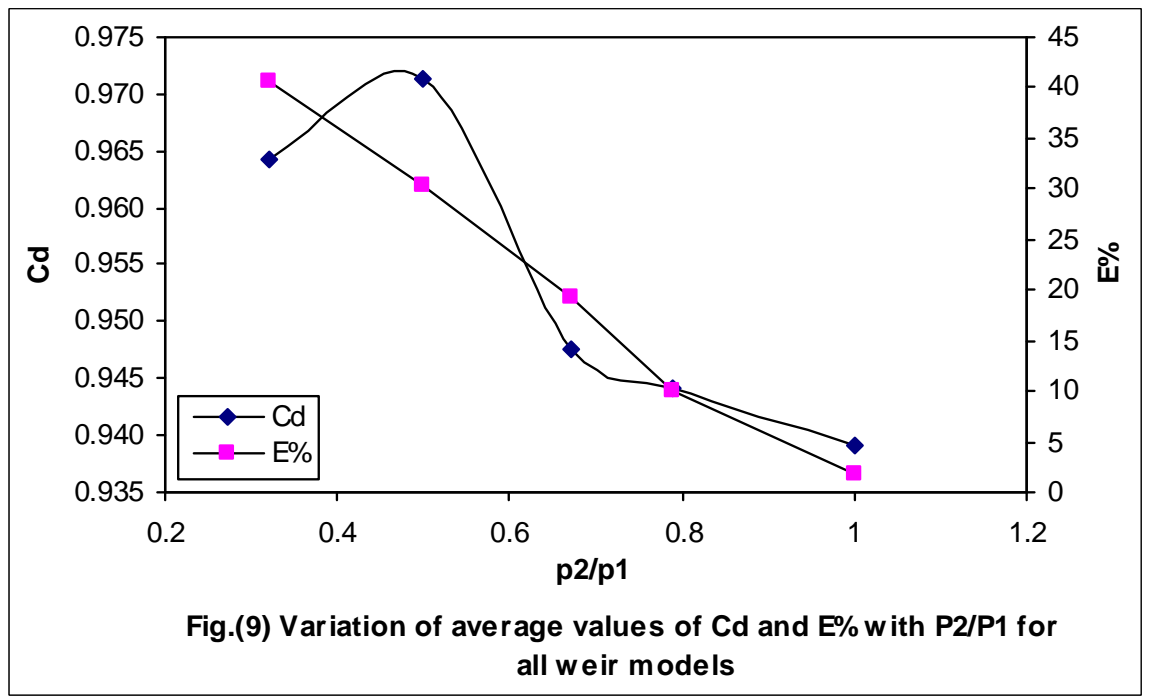

\section{Empirical Relations}

The relation between (h/P1) and (H/P1) for all models was shown in Figure (10). Furthermore, linear regression analysis was used to correlate h/P1 with $\mathrm{H} / \mathrm{P} 1$ in an empirical linear relation;

$\mathrm{h} / \mathrm{P} 1=0.64(\mathrm{H} / \mathrm{P} 1)-0.08$

With a correlation coefficient $=0.992$. 


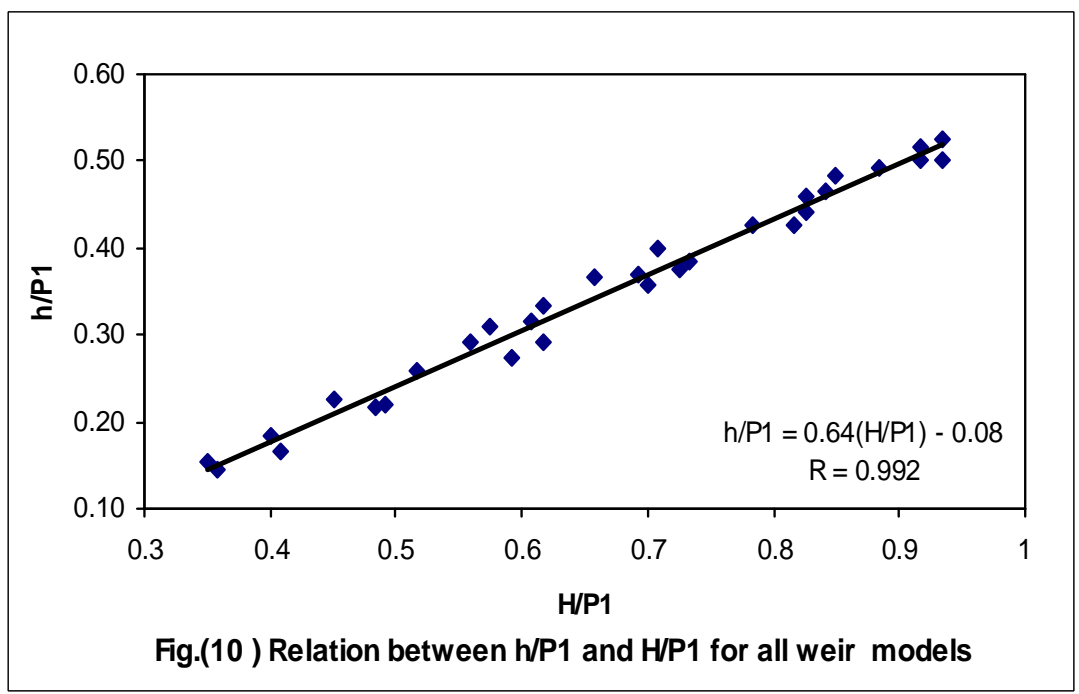

Based on equation (3), multiple nonlinear regression analysis was used to correlate $\mathrm{Cd}$ with both (H/P1) and (P2/P1) in an empirical power relation;

$C d=0.96\left(\frac{H}{P 1}\right)^{0.058}\left(\frac{P 2}{P 1}\right)^{-0.03}$

With a correlation coefficient $=0.83$.

The relation between $\mathrm{Cd}$ values predicted by equation (21) and experimental values of $\mathrm{Cd}$ is plotted in Fig. (11) which shows a good agreement. Another empirical power relation based on equation (19) was obtained for the variation of E\% with both (h/P1) and (P2/P1) (It was found that the effect of Fr2 was very little on $\mathrm{E} \%$ and it was neglected from the equation);

$E \%=6.56\left(\frac{h}{P 1}\right)^{-0.27}\left(\frac{P 2}{P 1}\right)^{-1.4}$

With a correlation coefficient $=0.94$.

A comparison between E\% values predicted by equation (22) and observed values experimentally is shown in figure (12). The maximum and minimum difference between them were 7.8 and -7.7 respectively. 


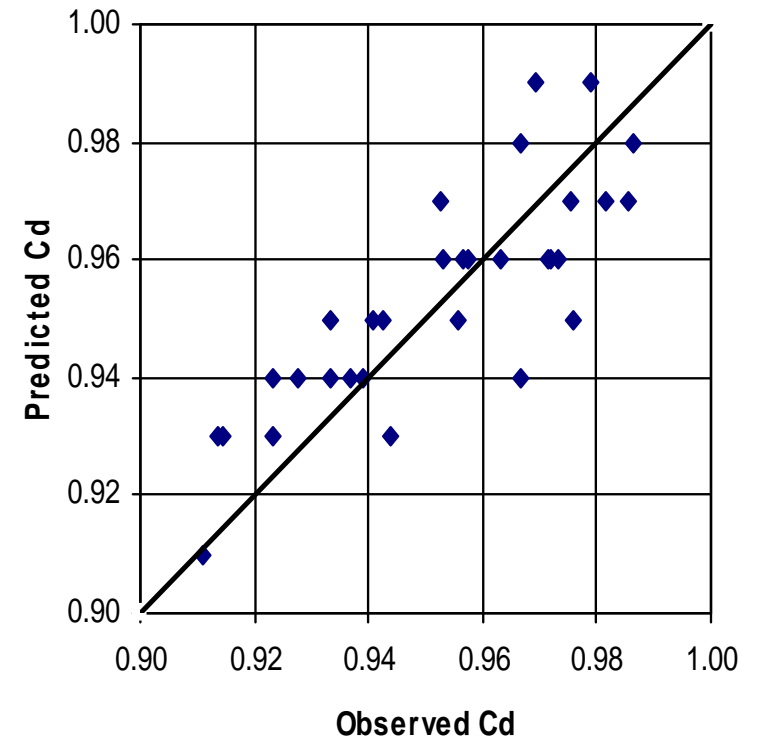

Fig.(11) Variation of predicted values of $\mathrm{Cd}$ with observed ones for all weir models

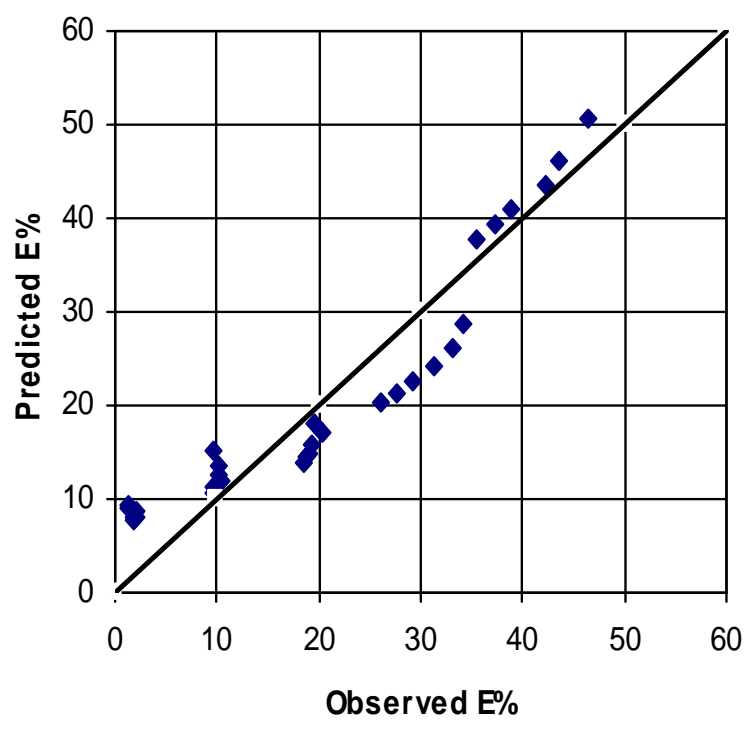

Fig.(12) Variation of predicted values of E\% with the observed ones for all weir models

\section{CONCLUSIONS}

Based on the results and analysis of this study. The following main conclusions were summarized as:

1- The U/S water flow heads can be measured correctly at a location when X/P1> $2 \mathrm{U} / \mathrm{S}$ of the weir.

2- Stepping broad-crested weirs will improve the discharge coefficient and the values of $\mathrm{Cd}$ were higher than in traditional weirs by $4 \%$.

3- The selection of the weir when $\mathrm{P} 2 / \mathrm{P} 1=0.5$ is the best to get higher $\mathrm{Cd}$. While the weir when $\mathrm{P} 2 / \mathrm{P} 1=0.32$ is the best selection for higher $\mathrm{E} \%$. The intersection point in Fig.(9) where the weir of $\mathrm{P} 2 / \mathrm{P} 1=0.4$ gave $\mathrm{Cd}=0.968$ and $\mathrm{E} \%=37$

4- A mathematical model to compute Cdth was modified depending upon momentum equation and gave $4 \%$ difference for traditional weir while for weir model of $\mathrm{P} 2 / \mathrm{P} 1=0.5$ gave difference of less than $2 \%$ in comparison with experimental values.

5- A linear relation was obtained to estimate $(\mathrm{h} / \mathrm{P} 1)$ in terms of $(\mathrm{H} / \mathrm{P} 1)$ as shown in Eq.(20).

6-Two empirical power relations were obtained, the first to estimate $\mathrm{Cd}$ in terms of the ratio for $\mathrm{U} / \mathrm{S}$ water head to $\mathrm{U} / \mathrm{S}$ weir height $(\mathrm{H} / \mathrm{P} 1)$ and the ratio of $\mathrm{D} / \mathrm{S}$ weir height to $\mathrm{U} / \mathrm{S}$ weir height (P2/P1) as shown in Eq. (21). While the second relation to estimate $\mathrm{E} \%$ in terms of the ratio for $\mathrm{D} / \mathrm{S}$ water head to U/S weir height (h/P1) and the ratio of $\mathrm{D} / \mathrm{S}$ weir height to $\mathrm{U} / \mathrm{S}$ weir height (P2/P1) as shown in Eq.(22). 


\section{REFERENCES}

1. Ackers, P., White, W.R., Perkins, J.A. and Harrison, A.J.M. (1978)," Weirs and Flumes for Flow Measurement", First Edition, John Wiley and Sons, Inc., New York, N.Y., PP. 133166.

2. Al-Talib, A.N.J. (2007)," Laboratory Study of Flow Energy Dissipation Using Stepped Weirs", MSc. Thesis, Engineering College, Mosul University.

3. Chamani, M.R. and Beirami, M.K. (2002)," Flow Characteristics atDrops", Journal of Hydraulic Engineering, ASCE, Vol. 128, No. 8, PP.788-791.

4. Chanson, H. (2001)," Hydraulic Design of Stepped Spillways and Downstream Energy Dissipaters", Dam Energy, Vol.11, No.4, PP. 205-242.

5. Clemmons, A.J., Replogle, J.A. and Bos, M.G. (1984), "Rectangular Measuring Flumes for Lined and Earthen Channels", Journal of Irrigation and Drainage Engineering, ASCE, Vol.110, No.2, PP.121-137.

6. Gonzalez, C. A. and Chanson, H. (2007)," Experiment Measurements of Velocity and Pressure Distributions on a Large Broad-Crested Weir", Flow Measurement and Instrumentation, Vol.18, PP.107-113.

7. Noori, B. M. and Juma, I. A. (2009),"Performance Improvement of Broad Crested Weirs", Journal of Al-Rafidain Engineering, Mosul University, Vol.17,No.2,PP.95-107.

8. Ramamurthy, A.S., Tim, U.S. and Rio, M.V.J. (1988),"Characteristics of Square-Edged and Round- Nosed Broad-Crested Weirs ", Journal of Irrigation and Drainage Engg., ASCE, Vol.99, No.2, PP.61-73.

9. Rao, N. S. L., and Rao, M. V. J. (1973),"Characteristic of Hydrofoil Weirs", Journal of Hydraulic Engineering, ASCE, Vol.99, No.2, PP. 259-281. 